\title{
Saer, nota y sinfonía
}

\author{
Julio Premat*
}

\section{Resumen}

En este artículo se trata de interrogar el proceso de escritura de los relatos del argentino Juan José Saer, y en particular I de su última novela, La grande, publicada póstumamente en el 2005, a partir de la relación entre el fragmento y el conjunto, metaforizados con elementos musicales (la nota, la sinfonía). Se analiza sucesivamente la relación entre la anotación prerredaccional y el flujo discursivo de las versiones finales (gracias a un análisis de algunos documentos genéticos), la relación que establece La grande con obras anteriores de Saer y finalmente la manera en que este libro postrero "cierra" la obra del escritor a partir de una plenitud fragmentada y de una recuperación contradictoria de cierta tradición novelesca. La hipótesis central sería que la tensión entre la parte y el todo es uno de los núcleos generativos de la producción de ese escritor, pero también un modo de construcción del conjunto de la obra y una manera de situarse en el panorama literario actual.

\section{Palabras clave}

Saer. La grande. Crítica genética. Música y literatura. Repertorio. Teoría de la novela.

\section{Nota y flujo}

Nunca sabremos cómo escribía Juan José Saer. A pesar de um trabajo meticuloso que llevamos a cabo sobre el material genético de Glosa y de El entenado ${ }^{1}$ y a pesar de la colaboración discreta, algo pudorosa y bonachona pero siempre benevolente del propio escritor, lo esencial que querríamos saber se nos escapa. Sólo cabe construir hipótesis y relatos, a la vez pertinentes y documentados, pero también ficticios, sobre el proceso. Nunca sabremos cómo escribía Juan José Saer: en esa frase y en los comentarios subsiguientes parafraseo el ensayo «El concepto de ficción », que comienza afirmando «Nunca sabremos cómo fue James Joyce » (Saer, 1997, p. 9) y suponiendo que el género biográfico, al no poder transmitir lo esencial de la vida y la actividad de un hombre en tanto que escritor (lo que realmente querríamos saber), no es más, en lo que atañe a la comprensión del proceso de creación, que un

\footnotetext{
* Université Paris 8.

${ }^{1}$ Me refiero al análisis del dossier genético de dos novelas de Saer llevado a cabo junto con Diego Vecchio y Graciela Villanueva para la edición Archivos (Saer, 2010). Los diferentes ejemplos citados figuran en el dossier genético allí publicado.
} 
género de ficción (o sea, un discurso ni cierto ni falso). Escribir sobre la escritura de Saer no es, entonces, un gesto de transmisión de una verdad documentada sino el esbozo de una construcción hipotética que permite, empero, pensar desde otro lugar la producción del santafesino.

A la hora de justificar la elección de la zona como espacio delimitado y recurrente para sus ficciones, Saer citaba a menudo a Faulkner, el que habría entendido que en el tamaño de una estampilla podía hacer entrar todo lo que él quería, el mundo entero. La afirmación se refiere a la invención de un territorio como manera de, gracias a un particularismo extremado, situarse en lo universal. La parte, la estampilla, que puede ser un todo: ese principio también rige la construcción del corpus saeriano y la relación que los textos establecen entre sí: una anécdota, un personaje lateral, un relato breve, van dando lugar, a lo largo de los años, a novelas sofisticadas. La sistemática amplificación prueba, con un efecto retrospectivo, que los mínimos elementos que componen un conjunto narrativo son potencialmente expandibles, contienen una insólita complejidad: en En la zona (primer libro de cuentos, de 1960) estarían todas las novelas de Saer. Cada libro es así el repertorio virtual de lo que se escribirá más tarde. Por lo tanto, volviendo al proceso de creación y extrapolando, sería concebible postular que en cada gesto de escritura, en cada documento preparatorio, en cada marginalia o en cada esquema prerredaccional de sus novelas, puede observarse todo el proyecto, toda la estética, el conjunto de la obra.

Muchos elementos distintos tolerarían un análisis en la orientación indicada. Me limito a uno, la relación entre notas breves y dispersas con la redacción lineal de la versión casi definitiva de los textos. Sabemos que el trabajo preparatorio de cada libro era un proceso que duraba a veces años y que esa preparación se llevaba a cabo ante todo mentalmente. Lo que queda de esos tanteos alrededor de un proyecto son hojas sueltas con anotaciones dispares. En esas hojas no figuran ideas generales ni resúmenes, ni visiones panorámicas, y ni siquiera borradores consecuentes, sino frases cortas de origen muy diverso: notas de lectura, traducciones, informaciones digamos enciclopédicas, muy escuetas ideas argumentales, y ante todo expresiones, frases, chistes, juegos de palabras, etc. Son, si se quiere, instantáneas discursivas, mínimos espacios de escritura. O sea, que el primer paso del trabajo preparatorio está constituido, textualmente al menos, por una serie de fragmentos, núcleos, brevísimos segmentos o partes minúsculas de un todo todavía inexistente. La nota rápida, efectuada en papeles diversos y sin ninguna organización material, contiene un hallazgo, algo que « surge», algo del orden de la inspiración y que dará lugar, posteriormente, a transformaciones que permitirán su inserción en el conjunto.

A veces leemos borradores de frases que se encontrarán luego, cobrando todo su sentido, en el texto definitivo. Otras veces son citas que, desplazadas de su contexto de origen e insertadas en las anotaciones saerianas, se integran armoniosamente en el estilo del escritor santafesino. Pero la mayor parte de las veces, la anotación parece ser un ejercicio de estilo, una gama musical hasta encontrar el tono requerido, hasta encontrar el «la » (o el « la mayor»). Tomando ejemplos de Glosa: el tono en el tipo de imágenes («La piel como espejo del mundo »), de reflexiones («La culpa es siempre anterior al crimen »), en bromas o agudezas: 
UN PECOSO = como si le hubieran tirado mierda en la cara y se hubiese atajado con un colador.

-Está bebido -dice Cuello. -No. Está en pedo -dice Tomatis.

ESCUELA + SECUELA + FRANELA + FRANCACHELA = NOVELA.

Se trata, explícitamente, de practicar el propio estilo o manera, e inclusive de repasar un idiolecto coloquial argentino, como en la larga lista que figuraba en el revés de un sobre blanco y de la cual transcribo sólo el inicio:

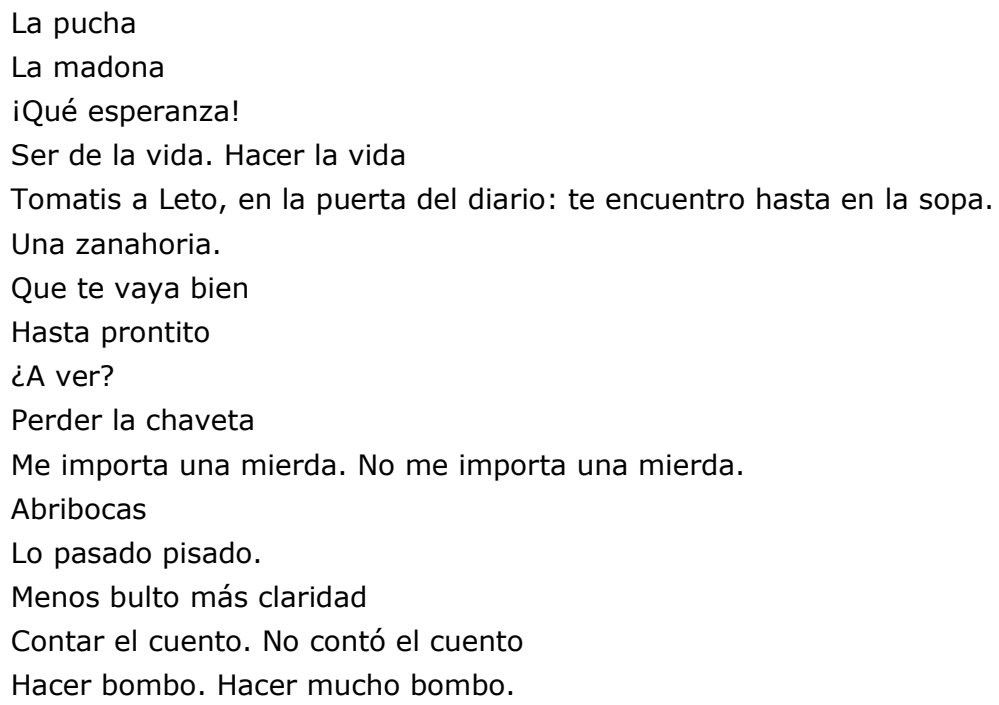

En este último ejemplo, la dimensión digamos musical es evidente (son « acordes » de un hablar argentino), así como su función: en la lista de expresiones surge una frase de Tomatis que figurará en la novela ( Te veo hasta en la sopa ») (Saer, 1995, p. 126). Esto ejemplifica las afirmaciones introductorias: retomando el repertorio de un habla coloquial argentina, haciéndolo sonar, se llega a la escritura personal.

Paralelamente, antes del comienzo efectivo de la redacción, otros dos gestos son a su vez asociables a la idea de lo mínimo como espacio productivo. Uno es el hallazgo del título, que da lugar a tanteos, búsquedas bibliográficas y largas reflexiones (en una palabra, en un juego de palabras, estaría la novela entera). Así, Glosa se llamó primero Hacia. Y la escritura definitiva está precedida por el texto de las diferentes acepciones del término, copiadas del diccionario de la Real Academia; de nuevo: en esa definición polisémica, en ese repertorio de sentidos del término-título está, ya, toda la novela. El otro gesto, es la escritura múltiple, cuidada y repetida de los incripts: la primera frase, las primeras frases, son el objeto de un cuidadísimo trabajo, como lo son, en parte, los escripts (escritos mucho antes de terminar la redacción del texto). Según Saer, encontrar el inicio era la etapa central para poder escribir y, durante la escritura, tenía que saber siempre cómo terminaba el relato (cómo terminaba no quiere decir, repito, una peripecia o un desenlace en el sentido tradicional, sino un fragmento de discurso: con qué palabras, exactamente, terminaba). El escritor lo ilustraba con una analogía pampeana: escribir era como esas 
carreras cuatreras, en las que hay falsas partidas, antes de que se ponga en movimiento la verdadera carrera, lo que está verdaderamente en juego. En todo caso, dar con el tono justo de un fragmento presupone el surgimiento del conjunto.

Después la escritura aparece como un flujo ininterrumpido, sin borradores, sin arrepentimientos, sin transformaciones importantes. Una palabra después de la otra, una frase después de la otra, con un ritmo lento (cuatro años para escribir Glosa) pero inalterable. A pesar de la complejidad de planos temporales, intrigas y personajes de Glosa, la novela está escrita así, como si fuese una totalidad preexistente al momento de la creación, como si el escritor siguiese el dictado de una paciente escritura mental, trabajosamente preparada por la nota, por el fragmento. Las partes terminan conteniendo y produciendo el todo.

En ese sentido, algunos testimonios permiten reconstruir una escena, quizás legendaria, la de Saer escribiendo, sentado frente a los prolijos cuadernos que usaba, con varios bolígrafos de colores distintos y anotaciones en minúsculos papeles alrededor de la página en blanco, como un marco fragmentado que permite la trabajosa pero mágica coagulación del flujo, aparentemente lineal, de su relato. De la nota al flujo, del rompecabezas lacónico a la página escrita, del repertorio a la literatura, de la frase breve a ese espacio fugaz de coherencia, esa breve epifanía, ese instante inteligible y armónico ante un mundo inestable, ininteligible, despedazado.

\section{Nota y tango}

De lo que precede se puede deducir, entonces, una analogía entre procesos de escritura y modos de constitución del corpus saeriano. Por un lado y como dijimos antes, el mínimo fragmento que da lugar a una expansión y a una forma paradójica de plenitud. Por el otro el recurrente modelo musical (tono, ampliación, variación) que podría aplicarse al proceso, modelo musical que, vía el formalismo latente y la nostalgia por la forma poética, es operativo en toda la obra. Expansión y música: esta constatación lleva a La grande (Saer, 2005) novela cuyo título remite, entre otras cosas, a una sinfonía (la sinfonía número nueve de Schubert, subtitulada « La grande »). Una novela que se inscribe en una amplitud narrativa y en un tempo inéditamente lentos (o sea en la extensión y dimensión de lo sinfónico), novela que utiliza, desprejuiciadamente, mecanismos narrativos bastante tradicionales y que prolonga múltiples hilos argumentales diseminados en la obra anterior, introduciendo de paso otras tramas que, de haberse prolongado, podrían haber dado lugar a un sinnúmero de nuevas variaciones en la obra. Es decir que la novela retoma todo un repertorio de lugares, personajes, discursos y peripecias (convierte a todo lo escrito en borrador preparatorio), pero también podría haber funcionado como otro borrador, como un nuevo repertorio. Sin embargo, y antes de continuar me parece importante acotar que el título también incluye, por supuesto, una distancia burlona (la referencia a la lotería, a un « sacarse la grande »), ironía que impone cierta prudencia a la hora de juzgar el aparente clasicismo del texto o su ambición panorámica. Dicho esto, cierto es que la novela plantea una totalidad, o una eventual totalidad, de cara a los relatos ya escritos -al resto de la obra de Saer- vistos como una serie de fragmentos o partes que, retrospectivamente, parecen haber ido preparando, a lo largo de los años, este sonoro allegro final. 
En esta perspectiva, lo primero que debemos subrayar es la revisión o reconstrucción del corpus que La grande lleva a cabo. Mucho podría escribirse al respecto. Elijo dos operaciones, que me parecen las más evidentes. Primero, algo que tiene que ver con el nombre de la novela y que no deja de ser problemático. La grande, desde el título, se instaura como la otra cara del otro libro de Saer que tiene un título musical, el nombre de una nota, La mayor (1976) (Saer, 2001, p. 123-212): la novela aparentemente total, la más clásica, el conjunto panorámico, dialoga así con el conjunto más fragmentado o entrecortado de la producción, el más extremista o experimental. El gesto, es importante señalarlo, le atribuye a la radicalidad negativa de la escritura un lugar privilegiado en la definición de un proyecto que, unos treinta años después, culminará entonces con esta novela «tradicional ».

La mayor contiene dos relatos consecuentes que, más que cuentos cerrados son episodios dislocados pero significativos de una historia no narrada (« La mayor », « $A$ medio borrar »), y que a la larga irán definiéndose como textos fundamentales en la obra, tanto temática, argumental como estéticamente. La depresión de Tomatis, la partida de Pichón, la relación de Washington con los jóvenes intelectuales de la ciudad, el secuestro del Gato, sugeridos aquí, volverán, una y otra vez, ampliados y transformados, en los textos posteriores. El libro contiene también una miscelánea de textos brevísimos, genéricamente híbridos (no siempre narrativos y no del todo ensayísticos) que figuran bajo el subtítulo de « Argumentos ».

«La mayor », el texto que le da el título al conjunto, se caracteriza por su radicalidad; es una experiencia límite en donde se ofrece una versión legendaria de la escritura en la óptica saeriana: la negatividad frontal, el escepticismo absoluto, la imposibilidad de prolongar o repetir los gestos de la literatura heredada (en este caso, Proust), la exposición aguda de una relación crítica con el lenguaje, pero también la puesta en escena del paso de la nada, el borrado, el pesimismo a un esbozo de recuerdo, de relato, de representación. Cortar con el pasado, afirmar una lucidez negativa, ganar por lo tanto una autonomía, una independencia y, tan heroica como modestamente, empezar de nuevo la tarea de nombrar el mundo. En « La mayor » se expande un modelo musical explícito, presente en el título, en los juegos de repeticiones y variaciones sonoras del texto y también en un documento preparatorio que pude consultar, en el que Saer enumera una serie de temas -en el sentido musical- que irán apareciendo en su relato: la escritura parece ser entonces el « tocar » o « ejecutar » determinado número de motivos preestablecidos. Si la forma y el esquema son etapas esenciales para la escritura en Saer, aquí la partitura sería el modelo de una formalización.

La proyección hacia la obra futura es todavía más evidente en « A medio borrar », si se lo juzga a partir de los relatos posteriores. Allí se narra una partida de la zona que sitúa a la escritura del lado de la pérdida (el destierro), la anulación de la identidad (Pichón busca en vano a su otra mitad, a su hermano gemelo, el Gato) y del cataclismo (la inundación que destruye la ciudad). Pocos años después, El entenado retomará, esta vez en una esfera mítica, estas dos fábulas personales: la escritura como paso de la nada radical y arcaica a la palabra balbuceada, y la escritura como fruto de un proceso de partida, pérdida y reaprendizaje. Y más allá de esta proyección 
en la historia, « La mayor » y «A medio borrar » serán esos fragmentos que llevan dentro, sin saberlo todavía, buena parte de las novelas por escribirse (Nadie nada nunca, Glosa, La ocasión, Lo imborrable, La pesquisa y, por supuesto, La grande).

Los « Argumentos», por fin, cuyo título tolera dos lecturas distintas. Por un lado, en tanto que proyecto, o resumen de proyectos (y por lo tanto, similares a las anotaciones que preceden la escritura de las novelas): se trataría de argumentos, en el sentido a la vez de tramas y de temas, capaces de dar lugar a textos más extensos. Una serie de posibilidades, una serie de promesas de libros todavía por escribirse, atisbos de una obra en ciernes. No son cuentos, por lo tanto, sino fragmentos de conjuntos inexistentes, huellas anticipadas de un universo narrativo quimérico ( $y$ algunos de ellos terminarán siendo efectivamente elementos de textos que se escribirán luego). Pero también, el título tendría un valor de afirmación polémica de una singularidad; estos textos que anuncian y preparan lo que se va a escribir serían argumentos en una discusión que busca defender la propia obra o probar su pertinencia. En la oposición al pasado literario y a la tradición, semejante serie de fragmentos, de posibilidades, de eventualidades de un todo hipotético, tienden a afirmar la pertinencia del proyecto, a la vez lúcido en su escepticismo y potente por las eventualidades que contiene. Por lo tanto, la alusión a una nota musical en el título del libro tendría un valor programático: es la nota determinante de todo lo que podrá tocarse o componerse luego, o sea que es un elemento breve y fugaz, que pretende ser el mínimo común denominador y el material con el cual se alzarán las grandes construcciones. Como en las notas preparatorias de la escritura arriba comentadas, se trata de dar con el tono, de dar el tono.

La mayor parece entonces fijar un repertorio de lo que será la obra de Saer, es decir una obra hecha de fragmentos ampliados, de situaciones, tonos y problemáticas irresueltas. Como si fuese posible fijar todos los temas, todas las tramas, todos los personajes, en un catálogo que luego, se va a expandir en novelas, La mayor sería un libro de fragmentos que incluye, al igual que una serie de estampillas, al mundo entero (o que incluye, al menos, al mundo narrativo de Saer). La mayor puede leerse así: el más saeriano de sus libros, el más cercano de los mecanismos de producción -por esa, digamos, supervivencia de la nota, de lo efímero-, pero también el más extraño y, sin duda, el más programático, el más estrechamente relacionado con una reflexión metaliteraria y con los postulados de un proyecto. ${ }^{2}$ La mayor, La grande: la nota aislada que marca una tonalidad general (el la mayor) y el panorama que retoma, desarrolla y expone, como lo haría una sinfonía. El instrumento que ensaya un sonido inicial determinante (la nota) y el conjunto que, a partir de ese tono ya dado, puede tocar una compleja red de melodías (la sinfonía). La nota (lo anotado) y lo narrado (la novela). Nota y sinfonía: la articulación entre estos dos polos sirve de metáfora para ilustrar las afirmaciones precedentes sobre la fase genética.

\footnotetext{
${ }^{2}$ Ante todo porque se sitúa en una encrucijada esencial para la definición y la expansión del proyecto literario. Si bien Saer había publicado varios libros de cuentos que, al igual que sus dos primeras novelas, parecen proponer un repertorio de personajes y situaciones, estableciendo un tono de escritura para la obra por venir, es Cicatrices, una novela escrita en 1967, la que parece fijar definitivamente a la obra del lado de la novela (diez títulos editados entre 1969 y 2005). Los textos de La mayor fueron escritos entre 1969 y 1975.
} 
Mucho más brevemente, una segunda operación de relectura de la obra anterior que La grande lleva a cabo. Vimos que la relación con La mayor crea un efecto de reflexión del proyecto (una imagen) y sobre el proyecto (una afirmación de características), que incluye una fisura o un punto ciego en la aparente totalidad o clasicismo de esa novela póstuma. Pero más concretamente, es más que significativo que La grande funcione como una ampliación de dos textos breves, situados en las dos extremidades de la obra, un cuento de 1960 ( «Tango del viudo ») y otro del 2000 (« Recepción en Baker street $\left.\gg^{3}\right)$, en donde aparecen por primera vez sus dos protagonistas, Gutiérrez y Nula. Otra vez: el flujo y lo breve, la parte y el todo, más la impresión retrospectiva de que todo lo que Saer escribe estaba previsto desde el origen de los tiempos -desde las páginas inaugurales de la obra-. El primer ejemplo es, creo, el más interesante. En ese cuento con un título musical, poético y, digamos, vanguardista (un tango nerudiano de Residencia en la tierra), un escritor, Gutiérrez, decide renunciar a una mujer, renunciar a la ciudad (el texto narra los preparativos y la partida, y por lo tanto sería una primera versión de « A medio borrar »), y junto con esta doble pérdida, también decide renunciar a su obra literaria o en todo caso a la estética que predominaba en ella, quemando sistemáticamente sus manuscritos. Esta autodestrucción no implica un abandono de la literatura, sino un borrado de lo anterior (« No es que hubiera dispuesto abandonar la literatura; al contrario. Quería, en lo que a su ejercicio personal se refería, deslindar sus impurezas, terminar con aquellos borradores que ahora no servían para nada, olvidar la técnica »). En una página en blanco, se trata de poder empezar algo nuevo ( No ha quedado nada »). Gracias a este gesto, Gutiérrez piensa, en el ómnibus que lo aleja de la ciudad que, por fin, ha conquistado, «su independencia » (Saer, 2001, p. 493-498).

En La grande, después, con toda una obra hecha, Saer parece desandar esta trayectoria, retomando un fragmento del inicio de su producción («Tango del viudo ») y propulsándolo al lugar de texto fundador: destrucción de borradores juveniles, ruptura con un amor imposible y con la herencia literaria, partida de la ciudad, escritura a partir de la pérdida pero también de una autonomía, una singularidad y una soledad absolutas: así nace un autor en la versión saeriana. Destierro y aislamiento que darán lugar, una y otra vez, a regresos o a viajes a la ciudad: el regreso de Pichón, el viaje del entenado, el de Bianco en La ocasión, el del doctor Real en Las nubes, hasta el del propio Gutiérrez, que, en La grande, también regresa. A partir de ese texto de 1960, a la zona se vuelve o, al menos, desde lejos y con un repertorio propio, a la zona se la puede ahora escribir.

\section{Cabrilleos narrativos}

Esta perspectiva de intertextualidad interna, a la vez con el fragmento y con la radicalidad experimental, no es anodina a la hora de referirse a la relación de $L a$ grande con modelos novelescos y con la idea en sí de una totalidad. Pienso que la

\footnotetext{
3 Publicados respectivamente en En la zona (1960) y Lugar (2000), e incluidos ambos en los Cuentos completos (Saer, 2001).
} 
extensión, el uso de recursos narrativos tradicionales $y$, en alguna medida, el clasicismo de La grande, plantean problemas de recepción que la emoción suscitada por sus circunstancias de escritura y publicación quizás hayan disimulado. ${ }^{4} \mathrm{La}$ impresión de clasicismo de La grande se explica, en parte, porque la novela no se crispa, como otros textos de Saer, alrededor de la representación o de la posibilidad de dar cuenta de acontecimientos del pasado gracias al relato literario, sino que retoma formas tradicionales de la novela, y ante todo el valor de la intriga. ${ }^{5}$ Así, en ella se expande lo que el propio Saer calificaba como una característica esencial del género decimonónico: el « acontecimiento ». Consecuentemente, el despojo total, la nada del sentimiento y del acontecimiento, son condiciones necesarias, escribía en 1973, para encontrar « el camino de una invención positiva $»^{6}$. Sin embargo, La grande abunda en intrigas que, debe reconocerse, no desembocan en desenlaces, sino que se focalizan en detalles, narraciones laterales, prolepsis fulgurantes (impresiones de un viaje en bus entre Rosario y la ciudad, cosida de un botón, perspectiva de la vejez de Nula y su mujer, recuerdo de una primera relación amorosa, etc.), prolepsis que aunque tienen una textura a menudo narrativa, funcionan como las habituales epifanías que pululan en las obras anteriores de Saer: en vez de éxtasis ante un momento en que la percepción da una imagen armoniosa del universo, éxtasis ante el arranque y funcionamiento efímero de una anécdota. El acontecer, para utilizar una palabra típicamente saeriana, cabrillea, fugaz, en la corriente a veces monocorde de la trama.

Por lo tanto, la idea de una totalidad debe ser matizada: es un simulacro de totalidad. Porque en sus grandes líneas, La grande expone mucho más de lo que resuelve, acumula a veces informaciones que tejen argumentos complejos (por ejemplo alrededor del triángulo amoroso Nula-Lucía-Riera), pero que no avanzan de manera que justifique esa acumulación. A veces, inclusive, se frustran directamente

${ }^{4}$ El manuscrito, limpio, prolijo y corregido de La grande se interrumpe en la última parte de la novela, una especie de breve epílogo intitulado « Lunes ». La novela está dividida en siete días, de «Martes» a «Lunes»y la acción principal terminaba al final del « Domingo ». Lo que quedó, entonces, pasado en limpio en una computadora, prolijo y aparentemente listo para su publicación, son los seis primeros días, luego el título « Lunes», un subtítulo, « Río abajo », y la primera frase de ese epílogo: «Con la lluvia, llegó el otoño, y con el otoño, el tiempo del vino. » Saer trabajó en la sexta parte de la novela, el « Domingo », durante su enfermedad.

${ }^{5}$ Desde ya, podemos leer el clasicismo relativo de La grande siguiendo afirmaciones de Saer sobre El hacedor de Borges. Allí escribía, en 1971, que el clasicismo es un horizonte cambiante, sin formas estables y reutilizables, y que la experimentación no es en sí garantía de creación o de modernidad: « Uno de los modos más fecundos de experimentación, y que es tal vez el más pertinente, consiste en elaborar la idea de clasicismo, la de tradición, la de literatura, y organizarlas en una relación nueva. [.] Cuando un gran escritor que es al mismo tiempo un gran innovador decide practicar el clasicismo, modifica la idea misma de lo clásico, aportando a la obra, inconscientemente, toda su capacidad de innovación previamente interiorizada » (Saer, 1997, p. 191). El desenlace de una larga trayectoria de experimentación y de negación del género novelesco, que constituye paradójicamente La grande, puede ser leído a partir de estas tempranas afirmaciones. O sea, leer la novela, no como una novela experimental - lo que sería exagerado, claro está -, pero sí como una novela que intenta modificar la « idea misma de lo clásico ».

${ }^{6}$ Leído en «Narrathon », ensayo en el que se proponía hacer surgir sus escritos de una intemperie radical y un escepticismo total («todo es, necesariamente, no falso, sino erróneo ») (Saer, 1991, p. 147 y p. 150). La intriga, escribía en otro texto ensayístico (« Intriga y comercio »), es el fundamento de la narración comercial ya que es previsible, codificada y por lo tanto destruye la especificidad del escritor y el trabajo de descubrir lo que no se conoce gracias al relato (Saer, 1999, p. 173-174). 
las expectativas creadas. Es lo que sucede con el « Domingo », escena central, anunciada a lo largo de la novela, en la que se reúnen todos los personajes importantes y en la que, a decir verdad, pasa poco y nada. Cierto es que la novela quedó trunca pero, según se sabe, la última parte, el « Lunes », funcionaba como una suerte de epílogo. Por lo tanto, no es descabellado postular que no faltarían grandes revelaciones ni acontecimientos; y, sea como fuere, el texto publicado contiene sólo eso: lo que «pasa » en La grande es lo que «pasa » en ese almuerzo de domingo (o lo que no pasa en ese asado postrero que repite tantas otras comidas colectivas de la obra). Esta constatación remitiría a una de las ideas del proyecto del libro, que data del principio de los años 80: la de jugar transgresivamente con ese elemento esencial de la novela decimonónica, a saber la intriga (según declaraciones del escritor, la novela del «falso vanguardista » debía intitularse, por lo tanto, El intrigante, y ser la prolongación de Glosa, lugar que ocupará, finalmente, Lo imborrable).

Lo que antecede es seguramente cierto y seguramente Saer habría dicho cosas así en las entrevistas y declaraciones que acompañaban la publicación de cada uno de sus libros: no se trata, sin más, de un retorno aproblemático a la novela tradicional y a sus remanidos recursos, sino una manera personal de utilizar otros aspectos del género, y ante todo, el acontecer, tan denostado por el propio Saer. Y también, un experimentar con la extensión -o, mejor, con el ritmo narrativo y la duración-. Pero cualquier lector siente, intuitivamente, que algo más sucede en La grande, que hay algo diferente y de gran intensidad. Esa diferencia tiene que ver con una epifanía, también, pero en otro sentido: una epifanía de narrador, una libertad, un placer del detalle, del suceder, del recordar, del evocar, una entrañable posición ante el mundo y la palabra. Hay una plácida felicidad del relato en La grande, una serenidad en la evocación de las pasiones humanas, en particular de la sexualidad, muy presente en el texto. Esta felicidad de narrador no es ajena al momento de la escritura: aunque el proyecto inicial fuese de los 80 , es el Saer del 2000 , con toda una obra detrás y un verdadero reconocimiento público, el que escribe. Un escritor que se arriesga, por supuesto, lanzán dose en un libro diferente y de tal envergadura, pero también un escritor que se arriesga porque tiene, ya, menos que probar. Los primeros ensayos de Saer, los de fines de los 60 y los 70, tienden hacia la defensa de una misma posición o situación: la autonomía del escritor, su absoluta singularidad, la independencia, que pasa por un despojamiento radical, por una posición de descreimiento, marginalidad y soledad. En el momento de la escritura de La grande, treinta años después, las cosas han cambiado: la marginalidad ha terminado por volverse un modo de posición central, y en todo caso ya no hay, en el horizonte de creación de la obra, esas figuras y preceptos que, desde fuera, intentaban intervenir en una escritura que quería ser diferente. Al respecto, se podrían aplicar las afirmaciones de Saer sobre el Borges que, en 1960, publica El hacedor: «La negligencia casi triunfal del epílogo, en El hacedor, revela la serenidad de quien ha reencontrado, aun a través de una compilación displicente, la convicción de poseer una voz predestinada » (Saer, 1997, p. 192).

Quizás esto explique que al proyecto del falso vanguardista y de la experimentación con la intriga de los años 80 , se le hayan agregado otros, que tienen una fuerte connotación a la vez de autobiografía cifrada (como puede leerse en el personaje de Nula, que lleva el apellido de la madre de Saer y que tiene algunos 
recuerdos que son los del niño Juan José) y de irónico autorretrato (el de Gutiérrez, habitante de la zona que retorna, treinta años después, deseando recuperar la inmutabilidad de las cosas y la persistencia de lo pasado). La intriga, así, el acontecer, son mecanismos decepcionantes por un lado, pero por el otro, algo narran, una historia deseada, la de la propia vida (es decir, narran una historia que se anhela poder narrar). No es casual, en ese sentido, que las afirmaciones críticas de Saer sobre la imposibilidad de llevar a cabo un relato « cierto » « realista » se focalicen, sistemáticamente, en una desconfianza por el género biográfico: si algo no se puede narrar, conocer o mostrar es una vida, una vida de escritor, la propia vida: nunca sabremos cómo fue James Joyce, nunca sabremos cómo fue Juan José Saer. Entre las líneas de una profusión de intrigas y de una omnipresencia del acontecer, podemos sin embargo identificar en La grande, no un relato autobiográfico, claro está, sino un deseo, una ilusión, una nostalgia por ese tipo de relato. $O$, si se quiere, una modalidad de narración que, lateralmente, se acerca más o traza con mayor visibilidad, un tipo de autobiografía que incluye el escepticismo (porque recuérdese, leemos en « Narrathon » que « no puede saberse, del acontecer, nada ») (Saer, 1997, p. 150). Así funciona La grande: sus acontecimientos, proliferantes, no desembocan en verdades ni desenlaces, pero la dinámica del acontecer, desplegada, sugiere modos implícitos y entrecortados de narrar lo más íntimo, lo más arduo, lo que siempre se quiso saber.

En esa perspectiva, quizás sea útil recordar que La grande es, también, la novela más santafesina, en el sentido de la precisión topográfica, la evocación sensible, la fuerza de la representación. Volver a la ciudad, otra vez, pero para quedarse, como lo hace Gutiérrez y, de nuevo, intentar decir ese espacio que, como Saer lo afirma al comienzo de El río sin orillas, es « mi lugar: en él, muerte y delicia me eran inevitablemente propias » (Saer, 1991, p. 17). Treinta y pico de años después de su mudanza a París, sistemáticamente, como nunca antes, Saer recorre el mapa de la ciudad, traza calles e itinerarios, identifica constantes (el club de pescadores) y novedades (el hipermercado), fija olores, colores, impresiones, retoma recuerdos, se acerca y se impregna de esa ciudad, en donde lo existente y lo soñado, lo empírico y lo imaginario, se superponen ya, después de tanto tiempo, inextricablemente. $Y$ hay que notar también el contexto de producción. La grande se sitúa inmediatamente después de Lugar (2000), es decir después de cuentos que sugieren una ampliación vertiginosa del concepto de lugar: habiendo construido ya un espacio literario fuerte $y$ reconocible, su propio territorio, ahora, en esos cuentos, el mundo entero entra en él, en la estampilla. En ese libro, el lugar puede ser cualquier lugar; El Cairo, Chernobil, Cadaqués o Viena, son todos fragmentos de un universo propio, confundido con el mundo entero. Pero como una prolongación sorprendente de la afirmación de una universalidad del lugar y de su carácter, digamos, virtual, después de Lugar, en La grande Saer vuelve entonces, con una inédita meticulosidad referencial y evocativa, a la ciudad de Santa Fe. Plenamente propietario de ese mundo, lo despliega y hace funcionar con evidente placer, como si la universalización del libro precedente liberara su capacidad de nombrar el espacio de siempre, el espacio propio, esa infinita y enigmática estampilla. 
Concluyamos. Aunque, punto de partida, el fragmento parece contradictorio con la amplitud del conjunto en su versión final, retrospectivamente la parte mínima (la nota, el texto breve, la alusión) parece contener -era el caso de La mayor- lo que va a escribirse luego: en una frase, en un elemento nimio, está toda la obra (porque está allí, in nuce, el gesto de escritura posterior). El proceso transforma lo anterior en borrador y en repertorio de una obra futura. Al mismo tiempo, el resultado, el conjunto ya construido, no ofrece una plenitud cerrada sino que es, a su vez, un conjunto inconsistente, fisurado, hecho de fragmentos disponibles para nuevas ampliaciones. $L a$ grande aparece como desenlace de la dinámica entre la parte y el todo, junto con ese regreso a Santa $\mathrm{Fe}$, a la propia biografía, a la novela decimonónica, y a la reemergencia de una nostalgia por la totalidad, por la plenitud narrativa, por la inteligibilidad de la propia vida y del mundo, por un espacio de origen pleno y armonioso. También en «Narrathon », leemos una cita de Sartre: « La totalidad no puede ser más que imaginaria », de lo que Saer deduce que, por lo tanto, la «ilusión de dominar, sobrehumanamente, la totalidad, (es) la más infundada de las certidumbres ». Escribir sería abrir « grietas en la falsa totalidad »: a partir de estos preceptos se construye la obra (Saer, 1991, p. 149 y p. 157). Pero también podemos decir que se construye formulando una utopía descreída o esbozando un horizonte en el que se querría creer: la existencia o la hipótesis de una totalidad. La grande trabaja con esa totalidad, a la vez postulada e imposible, desplegada y frustrada, presente y ausente (como están, presentes y ausentes, la autobiografía y la ciudad de Santa $\mathrm{Fe}$ ). Se narran las fallas de una plenitud, pero también esa plenitud perdida, esa plenitud imaginada.

El final de la obra, La grande, resultado de cuarenta años de notas, partes o fragmentos, se nos presenta como un todo, como otro todo que refleja a su manera la obra escrita. Un todo inestable y fisurado. Refiriéndonos de nuevo a Borges: la estampilla es entonces el Aleph saeriano, en donde podría estar todo, es decir el lugar desde el cual observar simultáneamente al mundo entero (es lo que sugerían los cuentos de Lugar), pero, según lo recuerda a su manera La grande, aun en esa perspectiva mágica sobre una totalidad, falta algo, el ser amado, falta lo deseado, falta, para siempre, Beatriz Viterbo, de quien no queda más que una « reliquia atroz $\gg^{7}$. Por lo tanto, el todo no es sino una parte: de las breves imágenes de La mayor a los panorámicos lienzos de La grande, de la nota a la sinfonía, el funcionamiento es el mismo: La grande sigue siendo, en tanto que todo, una estampilla, una parte. La gran novela (intriga múltiple, punto de vista omnisciente, coherencia cronológica y causal, personajes estables y espacios homogéneos) se sitúa en contrapunto con lo más fragmentado, La mayor, y se interrumpe en el borde de esa totalidad, en el momento de esbozar una representación plena de esa ciudad y de ese hombre que escribe. Y no sólo porque la novela se termina con la primera frase de un epílogo, porque tiene un final trunco que abre y comienza, pero también porque se detiene allí, porque se detiene así.

\footnotetext{
${ }^{7}$ Según leemos en el cuento de Borges, « El Aleph » (Borges, 1977, p. 171).
} 
Ese todo inacabado, ese todo-parte, ilógico, informe, discontinuo, incompleto se parece a Santa Fe, por supuesto, pero también se parece a este lugar, a cualquier lugar, a todo lugar, se parece - quién lo hubiese dicho - a ese gran lugar, ilógico, informe, discontinuo, incompleto, que llamamos mundo.

\section{Bibliografía}

BORGES, Jorge Luis. El Aleph. Madrid: Alianza, 1977.

SAER, Juan José. El río sin orillas. Buenos Aires: Alianza, 1991.

Glosa. Buenos Aires: Seix Barral, 1995.

El concepto de ficción. Buenos Aires: Ariel, 1997.

. La narración-objeto. Buenos Aires: Seix Barral, 1999.

. Cuentos Completos (1957-2000). Buenos Aires: Seix Barral, 2001.

. La grande. Buenos Aires: Seix Barral, 2005.

Glosa, El entenado. Coordinador: Julio Premat. Madrid: Archivos, 2010.

\section{Abstract}

This article examines the writing process of the stories of Juan José Saer, from the relationship between the fragment and the whole. We will specifically study his last novel, La grande, published posthumously in 2005. The relationship between draft notes and the discursive flow of final versions, the relationship that La grande creates with previous works of Saer and lastly, the manner in which this final book "closes" the author's work will all be analyzed successively.

\section{Keywords}

Saer. La grande. Criticism. Music and literature. Repertories. Novel theory. 